\title{
A THEORY MODEL FOR DESCRIPTION OF THE ELECTRICAL SIGNALS IN PLANT PART I
}

\author{
Zhongyi Wang ${ }^{1}$, Lan Huang ${ }^{1, *}$, Xiaofei Yan $^{1}$, Cheng Wang ${ }^{2}$, Zhilong $\mathrm{Xu}^{2}$, \\ Ruifeng $\mathrm{Hou}^{2}$, Xiaojun Qiao ${ }^{2}$ \\ ${ }^{1}$ College of Information and Electrical Engineering, China Agricultural University, Beijing, \\ 100083, P. R. China \\ 2 National Engineering Research Center for Information Technology in Agriculture, Beijing, \\ 100097, P. R. China \\ * Corresponding author: Lan Huang, College of Information and Electrical Engineering, \\ China Agricultural University, Beijing, 100083, P.R. China, Email address: \\ biomed_hl@263.net, Tel: +86-10-62737778, Fax: +86-10-62737778
}

Abstract: The ion mechanism for membrane potential of higher plant was discussed in this paper. A modified Hodgkin and Huxley model was developed for description of the electrical signals in plant. Three individual components of ionic current were formulated in terms of Hodgkin and Huxley model. It include potassium current $\mathrm{I}_{\mathrm{K}}$, calcium current $\mathrm{I}_{\mathrm{Ca}}$, and anion current $\mathrm{I}_{\mathrm{Cl}}$. It model will provide a useful tool to simulate the electrical activity in cell of higher plants, which respond to environmental changes.

Keywords: $\quad$ electrical signals; model; Hodgkin-Huxley equation; higher plant

\section{INTRODUCTION}

Since 1873 when Burdon-Sanderson discovered bioelectrical activity following stimulation in plant (Burdon-Sanderson, 1873), most investigations were carried out to prove the existence of electrical signals in plant as in animal (Davies, 1987). In fact, environmental stimuli such as spontaneous changes in temperature, light or wounding can induce electrical signals at plant cells. With regard to action potential (AP), the plasma membrane is depolarized by temperature or electrical stimulation as observed in higher plants (Fromm and Spanswick, 1993; Fromm and Bauer,

Wang, Z., Huang, L., Yan, X., Wang, C., Xu, Z., Hou, R. and Qiao, X., 2008, in IFIP International Federation for Information Processing, Volume 258; Computer and Computing Technologies in Agriculture, Vol. 1; Daoliang Li; (Boston: Springer), pp. 637-643. 
1994); if the stimulus is up to a certain threshold to depolarize the membrane, an AP is generated. APs are rapidly propagated electrical messages that are well known. APs travel at constant velocity and maintain constant amplitude in animals. They usually present all-or-nothing feature after a stimulus reaches a certain threshold lead resulting in membrane depolarization, but increases in stimulus strength do not change its amplitude and shape. It is well known that the ionic mechanism of APs in animal axons depends on $\mathrm{Na}^{+}$channel, $\mathrm{K}^{+}$channel and $\mathrm{Ca}^{2+}$ channel; the quantitative model of APs was described by Hodgkin-Huxley equation (Hodgkin and Huxley, 1952). Variation Potential of plant is evoked by damaging stimulations (wounding by cutting or burning) and is characterized by decrease in magnitude and as it spreads away from the site of stimulus. The mechanism and pathways of AP or VP transmission in plants have been investigated by several researchers (Davies, 1987; Julien et al., 1991; Stankovic and Davies, 1996; Stankovic et al., 1998; Dziubinska et al., 2003; Dziubinska et al., 2001; Volkov et al., 2005). When electrical signals (fluctuations) are only locally generated and not transferred to the other parts of a plant, they are defined as Local Electrical Potential (LEP) (Lou, 1996). LEP is a subthreshold response induced by natural variations in environmental factors, such as soil water, fertilizer, illumination, air temperature, and humidity (Leng, 1998; Hu, 2003). Although the LEP cannot be transferred, it significantly influences the physiological state of a plant (Ren et al., 1993).

Unlike animals, there are significant differences of bioelectrical activity between the species or individuals in higher plant after the same stimuli, the sensitivity and threshold of the same species varied dynamically with different growth condition. The ion mechanism which channels involve excitation of plant cells was investigated in several higher plants. In summary, ion base of depolarization or repolarization was studied by using traditional electrophysiological methods (intracellular, extracellular recording and ion channel inhibitors) and modern electrophysiological methods (patch clamp technique). Some results support the view that $\mathrm{Ca}^{2+}$, $\mathrm{Cl}^{-}$and $\mathrm{K}^{+}$ions channel and proton pump via cytoplasmic $\mathrm{pH}$ and/or Ca changes in cytosol involve the electrical activity of higher plants cells (Trebacz et al., 1997).

In the late 1980s, several models of the electrical activity of single ion channel of plant cells were formulated (Schroeder, 1989; Van Duijn, 1993). Until now, few Studies on the quantitative description of electrical activity of whole cell in plant were reported, especially for simulating the electrical signals in plant induced by environmental variations. In the present study, we will establish an theory model to calculate the rest potential and change of membrane potential of plant cell evoked by environmental factors based on modifying Hodgkin and Huxley model ( $\mathrm{H}-\mathrm{H}$ model). $\mathrm{H}-\mathrm{H}$ model was 
based on experimental data that were available at that time from voltageclamp studies, which those data were subject to limitations in available voltage-clamp techniques and their application to animal. With the development of patch clamp technique (single-cell and single-channel recording techniques) in the $1980 \mathrm{~s}$, the limitations of voltage-clamp measurements were overcome and the intracellular and extracellular ionic environments of plant cells could be controlled. The data from patch clamp recordings not only provide the basis for a quantitative description of channel kinetics but also can indicate membrane ionic currents of a cell. The aim of us is to use published experimental data to provide formulation of a modified $\mathrm{H}-\mathrm{H}$ model to describe electrical signals in plant induced by stimuli. In this paper, the $\mathrm{Ca}^{2+}, \mathrm{Cl}^{-}$and $\mathrm{K}^{+}$ions current were included in the equation $\left(\mathrm{Na}^{+}\right.$ion current is a significant phase in $\mathrm{H}-\mathrm{H}$ model of animal, but not involve APs of plant cells) and change of $\mathrm{H}^{+}$was also taken into account (Trebacz et al., 1997; Maathuis et al., 1997; Krole and Trebacz, 2000). This paper focuses on the process for establishment of the equation.

\section{TRANSMEMBRANE POTENTIAL - A MODEL OF REST POTENTIAL}

In order to calculate the transmembrane potential, a model of steady state was shown in Fig. 1. According to published data of transmembrane potential from the experiment, the measured membrane potential are often more negative than those obtained form the Goldman-Hodgkin-Kazt equation written as formula (1) to give the diffusion potential (Taiz and Zeiger, 1998). Cells in stem and roots of young seedlings generally have membrane potentials of $-130 \mathrm{mV}$ to $-110 \mathrm{mV}$, whereas the calculated diffusion potential are always only $-80 \mathrm{mV}$ to $-50 \mathrm{mV}$. Thus, in addition to diffusion potential, the membrane potential has other component. The evidence of many researches indicates that the excess voltage is provided by the plasma $\mathrm{H}^{+}$ pump in steady state. Furthermore, the transmembrane potential should be given as (2).

$$
\Delta V=\frac{R T}{F}\left(\ln \frac{P_{K^{+}} C_{K^{+}}{ }^{o}+P_{C a^{2+}} C_{C a^{2+}}{ }^{o}+P_{C l} C_{C l}{ }^{o}}{P_{K^{+}} C_{K^{i}}{ }^{i}+P_{C a^{2+}} C_{C a^{2+}}{ }^{i}+P_{C l} C_{C l}{ }^{i}}\right)
$$

$\Delta \mathrm{V}$ being diffusion potential, $\mathrm{R}, \mathrm{T}$ and $\mathrm{F}$ having their usual meaning; $\mathrm{Pk}^{+}$ $\mathrm{PCa}^{2+}, \mathrm{PCl}^{-}$represent the membrane permeabilities for $\mathrm{K}^{+}, \mathrm{Ca}^{2+}, \mathrm{Cl}^{-}$, respectively.

$$
V_{m}=\Delta V+\frac{R T}{F} \ln \frac{H_{i}}{H_{O}}
$$


$\mathrm{Hi}$ and $\mathrm{Ho}$ being inside and outside $\mathrm{H}^{+}$concentration.

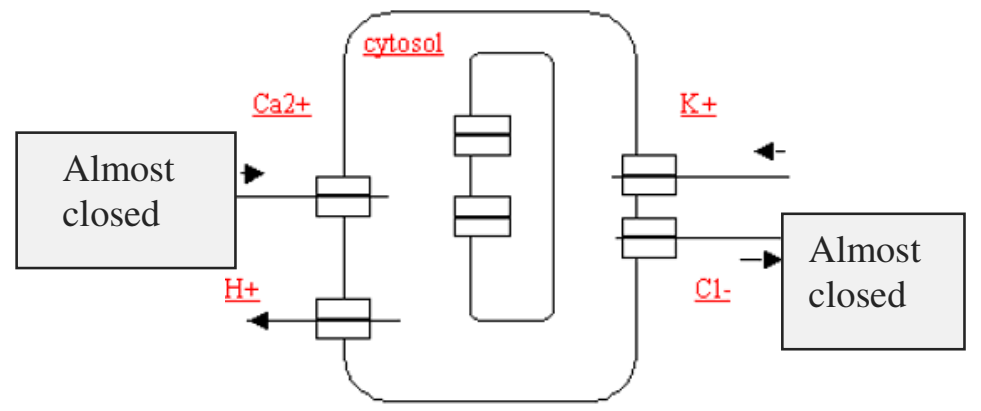

Fig. 1. A model of steady state

\section{A MODIFIED H-H MODEL OF HIGHER PLANT CELL}

Based on previous studies, a scheme illustrating the ion mechanism for membrane potential was shown in Fig. 2. A formula of transient depolarization induced by stimulation was given by (3). In the depolarization phases of Aps, $\mathrm{K}^{+}, \mathrm{Ca}^{2+}, \mathrm{Cl}^{-}$ion current take place, thus the $\mathrm{H}-\mathrm{H}$ model should be modified by using $\mathrm{Cl}^{-}$ion current instead of $\mathrm{Na}^{+}$ion current of animal. $\mathrm{K}^{+}$efflux and the activity of $\mathrm{H}^{+}$pump cause the repolarization of the membrane potential and complete return to the steady state. Here, we suggest that the change of $\mathrm{H}^{+}$ion efflux is a constant during whole procedure. In this model, the temperature induced membrane potential changes in higher plant cells is related to $\mathrm{Ca}^{2+}$ channel according to the physiological experimental results (Plieth, 1999). The general approach is based on a numerical reconstruction of the ventricular action potential by using Hodgkin-Huxley-type formalism. The rate of change of membrane potential $(\mathrm{V})$ is given by

$$
I s t i m=C m \frac{d V}{d t}+\sum I_{j}
$$

where $\mathrm{Cm}$ is the membrane capacitance, Istim is a stimulus current, and $\Sigma$ $\mathrm{Ij}$ is the sum of ionic currents: IK, a potassium current; ICa, a calcium current; ICl-, an anion current. The ionic currents are determined by ionic gates, whose gating variables are obtained as a solution to a coupled system of nonlinear ordinary differential equations. The ionic currents, in turn, change $\mathrm{V}$, which subsequently affects the ionic gates and currents. These differential equations about the ionic gates are of the form as formula (4) given by $\mathrm{H}-\mathrm{H}$ model. $\mathrm{y}$ represents any gating variable, $\mathrm{T} y$ is its time 
constant, and $\mathrm{y}^{\infty}$ is the steady-state value of $\mathrm{y} . \alpha \mathrm{y}$ and $\beta$ y are voltagedependent rate constants given as (5) and fitted from the published experimental data, $\mathrm{Ej}$ is the reversal potential of ion. Ion current can be written as formula (6); Especially, the phase of temperature influence on $\mathrm{Ca}^{2+}$ current described by (7), $\left[\mathrm{Ca}^{2+}\right]_{i}$ represent concentration of $\mathrm{Ca}^{2+}$ in cytosol, $\mathrm{T}$ is temperature. The free parameters are: $K_{l}, K_{m}$, const 1 to const6. The integration algorithm used to solve the differential equations is based on the Runge-Kutta methods.

$$
\begin{aligned}
& \frac{d y}{d t}=\frac{\left(y_{\infty}-y\right)}{\tau_{y}}, \tau_{y}=\frac{1}{\left(\alpha_{y}+\beta_{y}\right)}, y_{\infty}=\frac{\alpha_{y}}{\left(\alpha_{y}+\beta_{y}\right)} \\
& \alpha_{y}=\operatorname{const}(\alpha) \times f\left(\exp \left(V-E_{j}\right)\right) \\
& \beta_{y}=\operatorname{const}(\beta) \times f\left(\exp \left(V-E_{j}\right)\right) \\
& I_{j}=\operatorname{cons}_{j} \times y_{i}^{h} \times y_{n}^{m} \times\left(V-E_{j}\right) \\
& j=K^{+}, C l^{-} \\
& I_{\mathrm{Ca}^{2+}}^{1}=\mathrm{cons} \times y_{i}^{r} \times y_{n}^{r} \times\left(V-E_{\mathrm{Ca}^{2+}}\right) \\
& E_{\mathrm{Ca}^{2+}}=\text { const } 1-\text { const } 2 \ln \left(\left[\mathrm{Ca}^{2+}\right]_{i}\right) \\
& \frac{d\left(\left[\mathrm{Ca}^{2+}\right]_{i}\right)}{d t}=\left(\text { const } 3+\text { const } 4 \times I_{C^{2+}}^{1}+\frac{\text { const } 5 \times\left(-\frac{1}{2}\left(\frac{d T}{d t}-\left|\frac{d T}{d t}\right|\right)\right)^{2}}{K_{1}^{2}+\left(-\frac{1}{2}\left(\frac{d T}{d t}-\left|\frac{d T}{d t}\right|\right)\right)^{2}}-\right. \\
& \text { const } \left.6 \times \exp \left(K_{Q}\left(T-T_{0}\right)\right) \times \frac{\left[\mathrm{Ca}^{2+}\right]_{i}^{2}}{\left[\mathrm{Ca}^{2+}\right]_{i}^{2}+K_{m}^{2}}\right)
\end{aligned}
$$

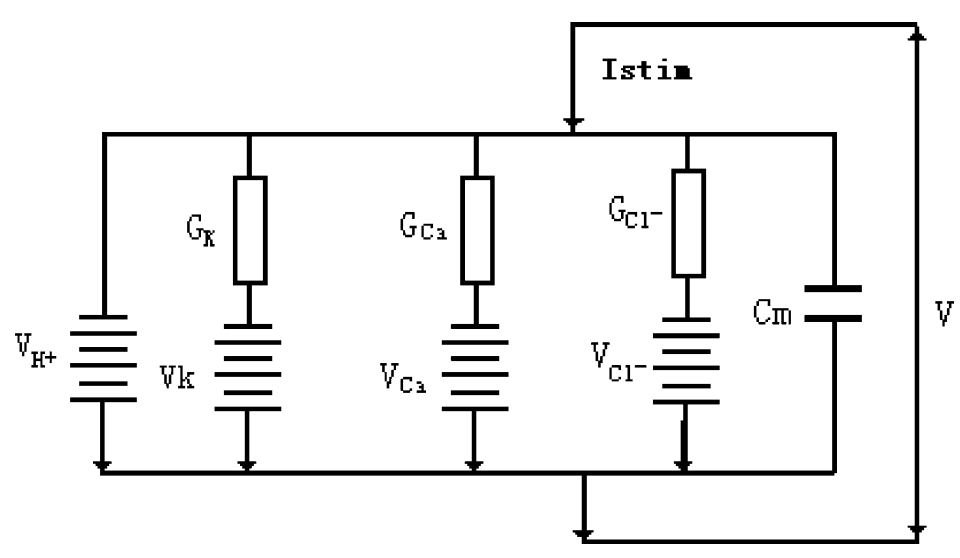

Fig. 2. A scheme illustrating the ion mechanism for membrane potential 


\section{SUMMARY}

A theory model has been developed by means of modifying HodgkinHuxley equation. Three predominant ionic current, potassium current, calcium current, and anion current involve in the equation to describe bioelectrical activity of higher plants. Our model allows us to study the influence of temperature parameter to reach threshold. Our results are in accordance with experiments. Most result and analysis of simulation by using the model will be reported in a forthcoming paper (Part-II).

\section{ACKNOWLEDGEMENTS}

This research was supported by the National Natural Science Foundation of China (Grant 60571027) and National High Technology Research and Development Program of China (863 Program, Grant 2006AA10Z202).

\section{REFERENCES}

Burdon-Sanderson J, 1873. Note on the electrical phenomena which accompany irritation of the leaf of Dionaea muscipula. Proceedings of the Royal Society of London, 21:495-496

Davies E, 1987. Action potentials as multi-functional signals in plants: a unifying hypothesis to explain apparently disparate wound response. Plant Cell and Environment, 10:623-631.

Dziubinska H, Fielk M, Koscielniak J, Zawadzki T, 2003. Variation and action potentials evoked by thermal stimuli accompany enhancement of ethylene emission in distant nonstimulated leaves of Vicia faba minor seedlings. Journal of Plant Physiology, 160:12031210.

Dziubinska H, Tredeusz K, Zawadzki T, 2001. Transmission route for action potentials and variation potentials in Helianthus annuus L. Journal of Plant Physiology, 158:1167-1172.

Fromm J, Bauer T, 1994. Action potentials in maize sieve tubes change phloem translocation. Journal of experimental botany, 45:463-469.

Fromm J, Spanswick R, 1993. Characteristics of action potential in willow (Salix vimnlis. L). Journal of experimental botany, 44:1119-1125.

Hodgkin AL, Huxley AF. A quantitative description of membrane current and its application to conduction and excitation in nerve. Journal of Physiology, 1952, 117:500-544.

$\mathrm{Hu} \mathrm{JH}, 2003$. Measurement and research on vegetal bioelectricity under water stress, Dissertation. Ji Lin University, China.

Julien JL, Desbiez MO, De Jaegher G., Frachisse JM, 1991. Characteristics of the wave of depolarization induced by wounding in Bidens pilosa L. Journal of Experimental Botany, 42:131-137.

Krole, Trebacz K, 2000. Ways of ion channel gating in plant cells. Annals of Botany, 86:449469.

Leng Q, 1998. Modulation effect of acetycholine on stomatal behavior and signal transduction in higher plant. Ph.D. Dissertation, China Agriculture University, China. 
Lou $\mathrm{CH}$, 1996. The messenger transmission of chemical wave in higher plant. Acta. Biophysics. Sinica, 12(4):739-745.

Maathuis FJM, Ichida AM, Sanders D, Schroeder JI, 1997. Roles of higher plant K+ channels. Plant Physiology, 114:1141-1149.

Plieth C, 1999. Temperature sensing by plants: calcium-permeable channels as primary sensors - a model. Journal Membrane Biology, 172:121-127.

Ren HY, Wang XC, Lou CH, 1993. The universal existence of electrical Signals and its physiological effects in higher plants. Acta Phyto-physiological. Sinica, 19(1):97-101.

Schroeder JI, 1989. Quantitative analysis of outward rectifying K channel currents in guard cell protoplasts from Vicia faba. Journal of Membrane Biology, 107:229-235.

Stankovic B, Davies E, 1996. Both action potentials and variation potentials induce proteinase inhibitor gene expression in tomato. FEBS. Letters, 390:275-279.

Stankovic B, Witters DL, Zawadzki T, Davies E, 1998. Action potentials and variation potentials in sunflower: An analysis of their relationships and distinguishing characteristics. Physiologia plantarum, 103:51-58.

Taiz L, Zeiger E, 1998. Plant physiology. Sinauer Associates INC., USA, 130-131.

Trebacz K, Simonis W, Schonknecht G, 1997. Effects of anion channel inhibitors on lightinduced potential changes in the liverwort Conocephalum conicum. Plant and cell physiology, 38:550-557.

Van Duijn B, 1993. Hodgkin-Huxley analysis of whole-cell outward rectifying K+ currents in protoplasts from tobacco cell suspension cultures. Journal of Membrane Biology, 132: $77-85$.

Volkov AG, Dunkley TC, Labady AJ, Brown CL, 2005. Phototropism and electrified interfaces in green plants. Electrochimica Acta, 50:4241-4247. 